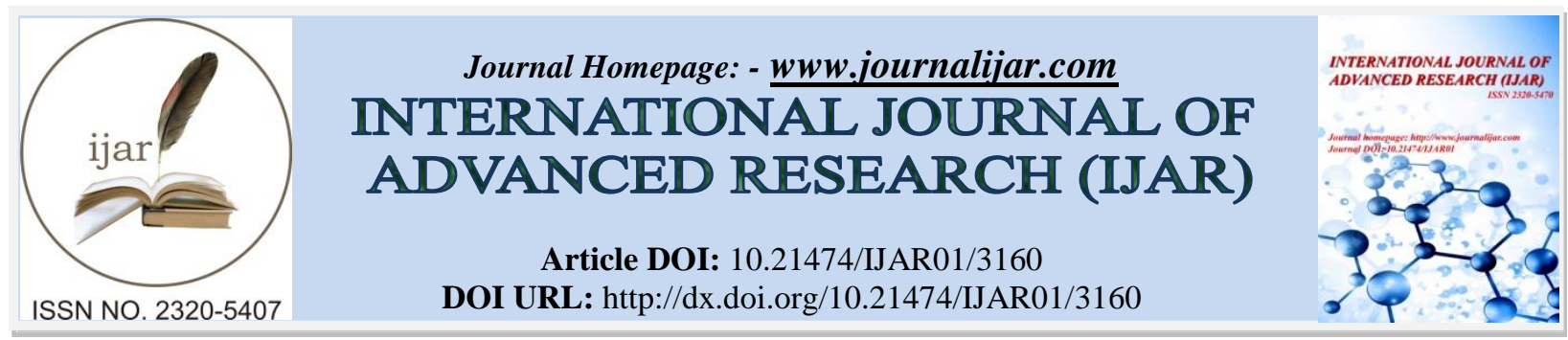

RESEARCH ARTICLE

\title{
RELATIONSHIP BETWEEN TACIT KNOWLEDGE SHARING, PROFESSIONALISM AND LIFELONG LEARNING IN ACCRUING PERSONAL COMPETENCIES
}

\author{
Preeti Choudhary ${ }^{1}$ and Lovy Sarikwal ${ }^{2}$. \\ 1. Phd Scholar, Gautam Buddha University, Greater Noida, India. \\ 2. Assistant Professor, Gautam Buddha University, Greater Noida, India.
}

\section{Manuscript Info}

Manuscript History

Received: 04 December 2016

Final Accepted: 07 January 2017

Published: February 2017

Key words:-

Tacit Knowledge Sharing, Personal

Competencies, Professionalism, Lifelong

Learning

\begin{abstract}
The knowledge-based view of competitive advantage acknowledges the importance of knowledge and human resource (HR) competencies as an organization's valuable assets (Hislop, 2003; Oltra, 2005). Intellectual ability of workers in particular tacit knowledge sharing and personal competencies are the essential pillars to build the oganisation's capital. However, research has shown that people are reluctant to share because employees' beliefs that their shared knowledge is useful to others than the personal benefits they gain, especially in a professional network. This study explores the relationship among tacit knowledge sharing, professionalism and lifelong learning. The conceptual framework consists of three capable factors i.e. tacit knowledge sharing, professionalism and lifelong learning and three groups of domain of both factors; professionalism (Professional challenge, professional facilitation and work engagement) and lifelong learning (self-efficacy, change readiness, and openness \& experience). This research contributes to a better understanding of tacit knowledge sharing and how that knowledge accrues personal competencies through professionalism and lifelong learning. Therefore, the proposed model might be used as an alternative theoretical model for evaluating the relationship among these factors in future studies.
\end{abstract}

Copy Right, IJAR, 2017,. All rights reserved.

\section{Introduction:-}

In the era of knowledge-based economy, resources and competencies are expected to be the crucial factors for organizations to survive in dynamic and competitive environment (Subramaniam \& Youndt, 2005; Teece, Pisano, \& Shuen, 1997). The new economy is based on the rules which emphasize the role of knowledge and competencies in shaping the competitive advantage of the organization. As a result, the value of the organisation is based on the resources inherent in the knowledge and competencies of its employees. To better use of competencies, employees always have to borrow from tacit knowledge of their colleagues. Thus it is also important to be aware of those competencies that encourage knowledge sharing (Csepregi, 2011).

The main issue of $\mathrm{KS}$ is associated with managing tacit knowledge rather than explicit knowledge (Bollinger and Smith, 2001) as people are reluctant to share it because employees' beliefs that their shared knowledge is useful to others than the personal benefits they gain, especially in a professional network (Chiu et al., 2006; Siemsen et al., 2007; Wasko \& Faraj, 2000; Wang \& Noe, 2010). Professionalism focuses on the question of what qualifications 
and acquired capacities, what competence is required for the successful exercise of an occupation (Englund, 2002:76). To maintain the status as a professional, the individual should continue to acquire new knowledge and practice his or her profession according to the code of the profession (Mottian, 2014). Successful societies and economies will depend on how well they enable these valuable assets to be shared, how well they learn from the knowledge they hold (Noor and Salim, 2011) and how they use it in their professions. The concept of professionalism is multifaceted in nature and, in spite of much research done in this field, it is still poorly conceptualised (Grinspun, 2007:22).

More recently, some studies empirically discussed the effects of knowledge sharing on various aspects of competencies. However, there is dearth of research of an integrative framework of tacit knowledge sharing, professionalism and lifelong learning together. Existing literature also shows that there is dearth of research which directly established a relationship between tacit knowledge sharing and personal competencies. Further there is lack of literature support that substantiates the interrelatedness between professionalism and lifelong learning. This study contributes to fill these gaps existing in the literature. Thus, the objective of this study is:

\section{Objective:-}

1. To study the relationship between tacit knowledge sharing and personal competencies.

2. To study the relationship between tacit knowledge sharing and professionalism.

3. To study the relationship between tacit knowledge sharing and lifelong learning.

4. To study the relationship between professionalism and lifelong learning.

\section{Literature Review:-}

\section{Tacit knowledge sharing (TKS)}

Tacit knowledge is unspoken and hidden and deeply rooted in action, procedures, routines, commitment, ideals, values, and emotions (Nonaka, Toyama, \& Konno, 2000). This type of knowledge can be found in everyday discussions, face-to-face informal meetings, and reports (Panahi et. al., 2012). This knowledge is a consequence of years of learning, gaining experience, and unspecified skill building within the mind, associations inexpressible by language, along with rules of inference and decision making (Ciechanowska, 2014). This knowledge resides in the mind of human being.

Tacit knowledge plays an important role in improving individual and organizational productivity and competitive advantage (Panahi et al., 2012). It is perceived as an important asset in improving quality of work, decision making, organization learning, productivity, competitiveness and major time saving for individuals and organizations (Herrgard,2000; Wahab et.al., 2010; Selamat and Choudrie, 2004). As a result, TKS is critical for individuals and organizations. Unlike explicit knowledge, tacit knowledge is more dependent to its human carrier (Grutter et. al., 1999). Even though the importance of tacit knowledge has been proved, unfortunately, in the work life, tacit knowledge is underrated.

\section{Personal competencies (PC):-}

According to Srivastava (2007), competencies means different things to different people. However, it is generally accepted as encompassing aptitudes (natural talent, susceptible to improvement), abilities (the practical application of a talent) and knowledge (necessary information for task achievement) (Lustri et. al., 2007). PC not only promotes learning, flexibility and adaptability but also contributes to the success of the entire organization. In order to enhance the productivity of knowledge workers, their competency enhancement and learning has to take place directly at their workplaces (Ley et al., 2008). The included items under PC are interpersonal skills, integrity, professionalism, initiative and lifelong learning. Without these attributes or competencies, the individual is not considered qualified. In this paper we have studied only two sub factors i.e. professionalism and lifelong learning.

\section{Professionalism:-}

Professionalism is a multidimensional concept that encompasses a number of different attributes including specialized knowledge, competency, honesty and integrity, respect, accountability, self-regulation and image etc. and, together, these attributes identify and define a professional. Professionals need to balance their own and their clients' interests through 'a voluntaristic commitment to a set of principles governing good practice and the realisation of these through day-to-day professional activities' (Hoyle and John 1995: 104). 
Professionalism is a trait that's highly valued in the workforce. The three concepts of knowledge, autonomy and responsibility, central to a traditional notion of professionalism, are often seen as closely interrelated (Furlong et al., 2000: 5). Professionalism is related to proficiency - the knowledge, skill, competence or character of a highly trained individual, as opposed to one of amateur status or capability (Wingrave and McMahon, 2016). While nearly all organisations have some form of professionalism curriculum, how best to promote and evaluate professionalism is unclear (Swick et. al., 1999; Kao, 2003).

\section{Lifelong learning (LLL):-}

LLL has been characterised as the "capacity to respond flexibly to changing circumstances, to learn throughout a career, and to integrate theory and practice...to deal capably with previously unmet situations" (Bligh, 1982), but also more broadly, embracing learning in a variety of formal, informal, planned and opportunistic settings (Candy, Crebert, and O'Leary, 1994).

LLL is never-ending process that involves and engages the learners of all ages in acquiring and using knowledge and skills. It is flexible, diverse and beginning with learning from families, communities, schools, religious institutions, workplaces, etc. which takes place at all times and in all places. It is attitudinal-that one can and should be open to new ideas, decisions, skills, or behaviors. This determines what an individual need to learn and how to make and carry out the learning plan (Collins, 2009).

Learning flows from a variety of activities, for example, observing how other people do something, discussing with others, asking someone, looking up information, trying something for oneself and learning from trial and error, and reflecting on all the previous activities (Bolhuis, 2003). LLL has emerged as one of the major challenges for the worldwide knowledge society of the future (Collins, 2009).

\section{Conceptual Model and Hypotheses:-}

\section{Tacit knowledge sharing and personal competencies:-}

Knowledge sharing practices in the whole organization are very important for preserving valuable heritage, learning new techniques, solving problems, creating core competences and initiating new situations (Hu et al., 2009; Huang et al., 2010; Law \& Ngai, 2008). Knowledge cannot be shared efficiently without having the adequate competences. To better use of competencies, employees always have to borrow from tacit knowledge (skills or experience) of their colleagues.

Sita Vanka, K. Sriram and A. Agarwal, in 5th International Conference on e-governance, ICEG (2007) also highlighted that there is lack of knowledge sharing, lack of personnel with appropriate background and aptitude and inadequate skill sets of personnel deployed in Indian e-governance system. Thus it is also important to be aware of those competences that are necessary for knowledge sharing (Csepregi, 2011). Knowledge sharing and competencies are the essential pillars in this knowledge era still the dearth of research of these two constructs together, exist in the organisations. Thus, the proposed hypothesis is as follows:

H1: There is an influence of tacit knowledge sharing on personal competencies.

A three-item scale of tacit knowledge sharing is developed by reference to a range of studies (Bock, Zmud, Kim, \& Lee, 2005; Holste \& Fields, 2010; C.P. Lin, 2007; H.F. Lin, 2007; Wang \& Wang, 2012). These scales contain (1) Employee experience; (2) Know- whom and know-where; (4) Lessons from past failures.

\section{Tacit knowledge sharing and professionalism:-}

Leach (2003) mentions professionalism as "a commitment to a high quality qualification training, an expectation of continuing learning, improving expertise among qualified practitioners and an enthusiasm for maintaining and developing the knowledge base on which the work of the service rests through study, research and recording and writing up developments". Researchers find that employees with high confidence in their ability to provide valuable knowledge are more likely to both donate and collect knowledge with colleagues (Lin, 2007).

Holste and Fields (2010) highlighted that the perceived competence and professionalism of the source of the tacit knowledge is a more critical determinant of willingness to use such knowledge. He discussed that use of tacit knowledge may present a somewhat larger risk to a professional employee than the act of sharing such knowledge. If a worker chooses to use and apply tacit knowledge provided by another, and the results are not as positive as 
expected, the recipient may need to present a responsible explanation to organizational management. Thus, the recipient of tacit knowledge must be confident about the consensus concerning the professional competence of the knowledge source. Knowledge sharing (KS) is important to promote the professional skill and competence in an organisation. Thus, the hypothesis proposed is:

H2: There is an influence of tacit knowledge sharing on professionalism.

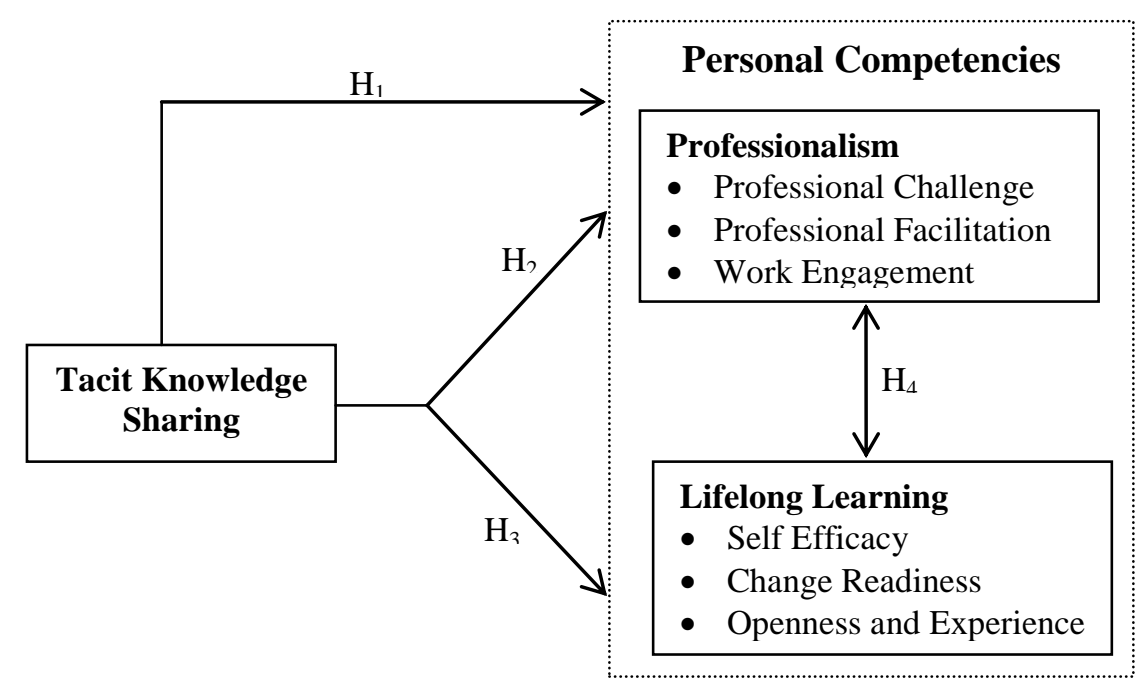

Figure 1.1:- Relationship between Tacit Knowledge Sharing and Personal Competencies

\section{Associated characteristics of Professionalism:-}

Professional Challenge: Professional challenge is a fundamental professional responsibility. In this context it is about challenging decisions, practice or actions which may not effectively ensure the safety or well-being of a child or young person or his/her family. Many professional challenges will be resolved on an informal basis by contact between the professional raising the challenge and agency receiving the challenge and will end there.

Professional Facilitation: With respect to professional facilitation, the focus on the facilitation of professionals by the actual organizations they are employed in rather than by professional organizations. In working with support groups if they change how they view their own role in creating change. Accordingly, the professional facilitation is more taking place within the setting of specific organizations than on an overall "purely professional" level. This means that the actual organization they are employed by is more important to them than the embeddedness in organizations of professionals. Professionals must know and do certain things to be professional (content) and they must be part of professional organizations (control) to acquire content and be regarded as professionals with special privileges (Noordegraaf, 2007).

Work engagement: Work engagement is a "positive, fulfilling work-related state of mind that is characterized by vigor, dedication and absorption (Bakker, Albrecht, and Leiter, 2011). Research has indicated that engaged employees are highly energetic, self-efficacious persons who exercise influence over events that effect their lives (Bakker, 2009; Schaufeli et al., 2011). This suggests that work engagement is important to enhance the discretion of organizations despite protocols and other routines (Butter and Jo Hermanns, 2011). Based on these finding, the subhypothesis proposed are:

H2a: There is an influence of tacit knowledge sharing on professional challenge.

H2b: There is an influence of tacit knowledge sharing on professional facilitation.

H2c: There is an influence of tacit knowledge sharing on work engagement.

Three components of professionalism domain are Professional Challenge, Professional Facilitation and Work Engagement are Adapted from shortened version of Utrecht Work Engagement Scale (Schaufeli et al., 2006). The components that have positive impact are selected, while the components that have negative impact have been eliminated. 
Table 1.1:- Items of the professionalism scales

\begin{tabular}{|l|}
\hline Professional challenge \\
1. To me working mainly means earning money \\
2. In my work, I have an important societal contribution \\
3. In my work, I can shape a number of my ideals in a practical way \\
\hline Professional facilitation \\
1. My work gives me a lot of opportunity to construct tailor-made solutions \\
2. In my work, I often face complex problems \\
3. In my work, I am supported by adequate instruments and methods \\
Work engagement \\
1. My work inspires me \\
2. I am proud of the work that I do. \\
3. I am enthusiastic about my work.
\end{tabular}

Tacit knowledge sharing and Lifelong learning:-

In the knowledge society knowledge is the only resource that grows when shared. It is not easy to convey this kind of knowledge. The only way this can happen if people work together in a harmonized environment, being ready to share their knowledge.

Knowledge is the engine of the modern economy all around the world. Keglovits (2013) highlights and supports the concept of the LLL, meaning people have to learn and develop in every stage of their life, in order to be a beneficial and valuable member of the economy. Learning is an active, goal-oriented, cumulative, and constructive activity, in which prior knowledge plays an important role in hindering or facilitating further learning (Shuell, 1988). Each and every person's knowledge and experience support and enlarge the collective knowledge. Even though the importance of tacit knowledge has been proved, unfortunately, in the work life this type of knowledge is underrated. Thus, the hypothesis proposed is:

H3: There is an influence of tacit knowledge sharing on lifelong learning.

Associated characteristics for lifelong learning:-

Self-efficacy: Self-efficacy (Bandura, 1986), is an enduring concept in human behaviour research, particularly in relation to learning (Pajares, 1997). It represents a person's beliefs and judgements about his/her ability to accomplish a task or succeed in some endeavour, and these beliefs can determine how people feel, think, motivate themselves and behave. The relationship between self-efficacy and learning is strong, and can be influential in different ways (Pajares, 2002) including the choices students make, the effort expended on a learning activity, perseverance and resilience, and the degree of stress and anxiety experienced whilst engaged in learning. Studies have found that self-efficacy is significantly related to personal goals and performance (Mone, 1994), as well as cognitive strategy (Pintrich and DeGoot, 1990) use in the organisation. Firmin and Miller (2005) argue that lifelong learners are motivated to learn through a positive attitude, confidence in themselves and the ability to manage negative feelings effectively. Therefore, individuals with high self-efficacy are more likely to be engaged in lifelong learning (Bath \& Smith, 2009).

\section{Change Readiness:-}

The concept of 'change readiness' has traditionally been examined in relation to psychotherapy and health behaviour concerns such as addiction and obesity (Prochaska, Redding and Evers, 1997), and also within the organisational context, examining workers adaptability, motivation, or willingness to change (e.g., Ingersoll et al. 2000). It is through the relationship to organisational research that change readiness has also been explored in relation to adult learning (Rogers, 1995; Cervero, 1985).

\section{Openness to experience:-}

Individuals who show openness to experience are described as '...curious, original, imaginative, creative, and unconventional and have a broad spectrum of interests' (Blickle, 1996, 338). Openness can impact on learners' motivation and engagement as well as their use of strategies and persistence after failure (Blickle, 1996). Also, along with need for achievement, openness to experience has been related to intelligence and creativity in a group of adults 
(Harris, 2004), as well as decision-making performance in a changing task context (Lepine, Colquitt and Erez, 2000). Moreover, in terms of lifelong learning, Barrick and Mount (1991) found that of the "Big-5" personality dimensions, openness was consistently related to job performance specifically through training proficiency across a range of occupations including all the professionals (Bath and Smith, 2009). Based on these finding, the subhypothesis proposed are:

H3a: There is an influence of tacit knowledge sharing on self efficacy.

H3b: There is an influence of tacit knowledge sharing on change readiness.

H3c: There is an influence of tacit knowledge sharing on openness and experience.

The General Self-Efficacy Scale (Sherer et al. 1982) comprises 3 items containing locus of control, interpersonal competence and self-esteem. The scale was designed to measure generalized feelings of competence rather than being specific to a particular situation/behavior. Goldberg's International Personality Item Pool (IPIP; 1999) includes an Openness to experience scale that includes emotionality, adventurousness and intellect. The third measure was adapted from Kriegel and Brandt (1996) who developed a measure of change-ready traits in relation to personnel and business management; contains three subscales; resourcefulness, adaptability and confidence. All the responses are made on a 5 -point Likert agreement scale $(1=$ strongly disagree, $5=$ strongly agree $)$. The snapshot of all scales with items is mentioned below.

Table 1.2:- Items of the lifelong learning scales

Self-Efficacy: General Self-Efficacy Scale (Sherer et al. 1982)

1. Locus of Control: I am a self-reliant person

2. Interpersonal Competence: I avoid confrontation with others

3. Self-esteem: When I make plans, I am certain I can make them work.

Change Readiness: Kriegel and Brandt (1996)

1. Resourcefulness: I explore everywhere to find solutions

2. Adaptability: I do not give up even if the things are not working out.

3. Confidence: I prefer to finish my work before deadline.

Openness to experience: Goldberg's International Personality Item Pool (IPIP; 1999)

1. Emotionality: I enjoy examining my feelings about myself and my life.

2. Adventurousness: I do not prefer to stick to doing things that I know.

3. Intellect: I am interested in theoretical discussions.

\section{Professionalism and lifelong learning:-}

As discussed in Collins (2009) study, Lifelong learning has emerged as one of the major challenges for the worldwide knowledge society of the future. G7-G8 group of countries named "Lifelong Learning" as a main strategy in the fight against Unemployment. He also discussed that Lifelong learning is now recognized by educators, governing bodies, accreditation organizations, certification boards, employers, third party payers, and the general public as one of the most important competencies that people must possess. Promoting lifelong learning as continuous, collaborative, self-directed, active, broad in domain, everlasting, positive and fulfilling, and applicable to one's profession as well as all aspects of one's life has emerged as a major global organizational challenge.

In many cases this learning will also involve knowledge development in the context of professional (or daily) life as new knowledge is needed to deal with innovation and new professionalism will be needed in such an organisation to understand and support new ways of learning and to create new learning environments (Weert, 2006). In other words, the concept of LLL has to enable meaningful education harmonized with one's professional and personal life. LLL is defined by EU Commission (2002) as all learning activity undertaken throughout life, with the aim of improving knowledge, skills and competence, within a personal, civic, social and/or employment, and related perspectives (Dondi, 2004). Thus, the hypothesis proposed is:

H4: There is interrelatedness between professionalism and lifelong learning. 


\section{Conclusion and Future Research:-}

Knowledge sharing and personal competencies practices in firms contribute to competitive advantage. The conceptual framework consists of two capable factors and three groups of domain of each factor; professionalism (Professional challenge, professional facilitation and work engagement) and lifelong learning (self-efficacy, change readiness, openness and experience). By proposing a model discussed the influence of tacit knowledge sharing on professionalism and lifelong learning which in turn lead to strong personal motivation, high productivity, competitiveness and organizational success. This study contributes to fill the gap existing in the literature. Therefore, the proposed model might be used as an alternative theoretical model for evaluating the relationship among tacit knowledge sharing, professionalism and lifelong learning in future studies.

A number of issues are open to future research. First, more items should be developed for the personal competencies scale, such that its psychometric properties can be adequately studied. Also, increasing the range of items will probably increase the variance of the scale and thereby enhance its success as a predictor in competition with the other aspects of professionalism and lifelong learning. This study will be followed by an empirical study to test the validity of the model. It is believed that this study will increase the understanding of TKS on professionalism and lifelong learning in accruing personal competencies among employees.

\section{Limitations:-}

This study has limitations. First, Constructs of both professionalism and lifelong learning will vary from individual to individual because of diverse workforce. Second, the credibility of tacit knowledge sharing can't be ascertained every-time as the employees reluctant to share it because they consider it important for themselves (Borges, 2012), as it can help them to remain valuable in the organization (Rehman et. al., 2011). The use of tacit knowledge may present a somewhat larger risk to a professional employee than the act of sharing such knowledge. If a worker chooses to use and apply tacit knowledge provided by another, and the results are not as positive as expected, the recipient may need to present a responsible explanation to organizational management (Holste \& Fields, 2010). Third, Implementation of personal competencies is difficult without organizational support.

\section{References:-}

1. Bakker, A. B. (2009): Building engagement in the work place. In R. J. Burke \& C. L. Cooper (Eds.), The peak performing organization (pp. 50-72). Abingdon, UK: Routledge.

2. Bakker, A. B., Albrecht, S. L. \& Leiter, M. P. (2011): Key questions regarding work engagement. European Journal of Work and Organizational Psychology, 20(1): 4-28.

3. Bandura, A. (1986): Social foundations of thoughts and action. Englewood Cliffs, NJ: Prentice Hall.

4. Barrick, M. R. and Mount, M.R. (1991): The Big-Five Personality dimensions and job performance- A metaanalysis. Personnel Psychology, 44(1): 1-26.

5. Bath, D. M. \& Smith, C. D. (2009): The relationship between epistemological beliefs and the propensity for lifelong learning. Studies in Continuing Education, 31(2): 173-189.

6. Blickle, G. (1996): Personality traits, learning strategies, and performance. European Journal of Personality, 10: 337-352.

7. Bligh, E. (1982): Professionalism and flexibility in learning. (Leverhulm Series No. 6 Ed.), Guildford: Society for Research into Higher Education.

8. Bock, G. W., Zmud, R. W., Kim, Y. G., \& Lee, J. N. (2005): Behavioral intention formation in knowledge sharing-Examining the roles of extrinsic motivators, social-psychological forces, and organizational climate. MIS Quarterly, 29(1): 87-111.

9. Bolhuis, S. (2003): Towards process-oriented teaching for self-directed lifelong learning- A multidimensional perspective. Learn Instruct,13(3): 327-347.

10. Bollinger, A. S. and Smith, R. D. (2001): Managing organizational knowledge as a strategic asset. Journal of Knowledge Management, 5(1): 8-18.

11. Borges, R. (2012): Tacit knowledge sharing between IT workers- The role of organizational culture, personality, and social environment.Management Research Review, 36(1): 89-108.

12. Butter, R. and Hermanns, J. (2011): Impact of experienced professionalism on professional culture in probation. European Journal of Probation, 3(3): 31-42.

13. Candy, P. (1991): Self-Direction for lifelong learning- A comprehensive guide to theory and practice. San Francisco, CA: Jossey-Bass. 
14. Candy, P., Crebert, G. and O'Leary, J. (1994): Developing lifelong learners through undergraduate education. NBEET. Canberra: AGPS

15. Cervero, R. M. (1985): Continuing professional education and behavior change- A model for research and evaluation. Journal of Continuing Education in Nursing, 16: 85-88.

16. Chiu, C., Hsu, M. \& Wang, E. (2006): Understanding knowledge sharing in virtual communities: An integration of social capital and social cognitive theories. Decision Support Systems, 42(3), 1872-1888.

17. Ciechanowska, D. (2014): The ability of tacit knowledge sharing as the competence needed in the knowledge economy, Qualification for the future. Proceedings of peer-reviewed scientific papers with international participation, pp. 114-120.

18. Collins, J. (2009): Education Techniques for Lifelong Learning. Radio Graphics, 29(2): 613-622.

19. Dondi, C., Edvinsson, B. \& Moretti, M. (2004): Why choose a game for improving learning and teaching processes? In: Pivec M., Koubek A. \& Dondi C. (Eds.). Guidelines for game based learning. Lengerich: Pabst Science Publ., 20-76.

20. Englund, T. (2002): Are professional teachers a good thing. Teachers' Professional Lives, Ch.4:76, by Ivor F. Goodson, Routledge.

21. Firmin, S. and Miller, C. (2005): Facilitating the development of lifelong learners through e-communication tools. Paper presented at ASCILITE Conference, 4-7 December, Brisbane, Queensland.

22. Furlong, J., Barton, L., Miles, S., Whiting, C., \& Whitty, G. (2000): Teacher Education in Transition, Buckingham, Open University Press.

23. Goldberg, L. R. (1999): A broad-bandwidth, public domain, personality inventory measuring the lower-level facets of several five-factor models. In Personality Psychology in Europe Vol. 7, ed I. Mervielde, I. Deary, F. De Fruyt, and F. Ostendorf, pp. 7-28. Tilburg, The Netherlands: Tilburg University Press.

24. Grinspun, D. (2007): Professionalism in Nursing. Healthy Work Environments Best Practice Guidelines. RNAO - Nursing Best Practice Guidelines Program, Registered Nurses Association of Ontario, Toronto, pp. 28-42.

25. Grutter, R., Stanowvska-Slabeva, k. and Fierz, W. (1999): Implementing a knowledge medium in a multicentered clinical trial. 32nd Hawaii International Conference on System Sciences (HICSS-32), Maui, USA.

26. Harris, J. A. (2004): Measured intelligence, achievement, openness to experience, and creativity. Personality and Individual Differences, 36: 913-929.

27. Herrgard, T. H. (2000): Difficulties in diffusion of tacit knowledge in organizations. Journal of Intellectual Capital, 1(4): 357-365.

28. Hislop, D. (2003): Linking human resource management and knowledge management via commitment: A review and research agenda. Employee Relations, 25(2): 182-202.

29. Holste, J. S. and Fields, D. (2010): Trust and tacit knowledge sharing and use. Journal of Knowledge Management, 14(1): 128-140.

30. Hoyle, E. \& John, P. (1995): Professional Knowledge and Professional Practice, London and New York, Cassell.

31. Huang, Q., Davison, R. M. and Gu J. (2010): The impact of trust, Guanxi orientation and face on the intention of Chinese employees and managers to engage in peer-to-peer tacit and explicit knowledge sharing. Information Systems Journal, 21(6): 557-577.

32. Hu, M. L. M., Horng, J. S. and Sun, Y. H. C. (2009): Hospitality teams-Knowledge sharing and service innovation performance. Tourism Management, 30: 41-50.

33. Kao, A., Lim, M., Spevick, J. and Barzansky, B. (2003): Teaching and evaluating students' professionalism in US medical schools, JAMA, 290:1151-1152.

34. Keglovits, B. T. (2013): Sharing Tacit Knowledge in an Organization, Hagga-hella-University of applied Science, unpublished thesis.

35. Knapper, C. and Cropley, A. J. (2000): Lifelong learning in higher education. London: Kogan Page.

36. Kriegel, R. and Brandt, D. (1996): Sacred cows make the best burgers. Sydney: Harper Business.

37. Lajos, S. and Csepregi, A. (2011): Competences found important for knowledge sharing- Investigation of middle managers working at medium and large-sized enterprises. The IUP Journal of Knowledge Management, 9(3): 41-58.

38. Law, C. C. H. and Ngai, E. W. T. (2008): An empirical study of the effects of knowledge sharing and learning behaviors on firm performance. Expert Systems with Applications, 34: 2342-2349.

39. Leach, T. (2003): Oh my country, how I leave my country-Some reflections on a changing probation service. Probation Journal, 50(1): 20-29.

40. Lepine, J. A., Colquitt, J. A. and Erez, A. (2000): Adaptability to changing task contexts-Effects of general cognitive ability, conscientiousness, and openness to experience. Personnel Psychology, 53: 563-593. 
41. Ley, T., Ulbrich, A., Scheir, P., Lindstaedt, S. N., Kump, B. and Albert, D. (2008): Modeling competencies for supporting work-integrated learning in knowledge work. Journal of knowledge management, 6: 31-47.

42. Lin, C. P. (2007): To share or not to share-Modeling tacit knowledge sharing, its mediators and antecedents. Journal of Business Ethics, 70(4): 411-428.

43. Lin, H. F. (2007): Knowledge sharing and firm innovation capability: An empirical study. International Journal of Manpower, 28(3/4): 315-332.

44. Lustri, D., Miura, I. K. and Takahashi, S. (2007): Knowledge management model-Practical application for competency development. The Learning Organization Journal, 14(2): 186-202.

45. Mone, M. A. (1994): Comparative validity of two measures of self-efficacy in predicting academic goals and performance. Educational and Psychological Measurement, 54: 516-529.

46. Mottian, S. D. (2014): Professionalism in nursing: A concept analysis. North-West University (South Africa). Potchefstroom Campus, pp. 25.

47. Nonaka, I., Toyama, R. \& Konno, N. (2000): SECI, Ba and Leadership- A Unified Model of Dynamic Knowledge Creation. Long Range Planning, Elsevier Science Ltd, 33: 5-34.

48. Noordegraaf, M. (2007): From 'pure' to 'hybrid' professionalism-Present-day professionalism in ambiguous public domains. Administration \& Society, 39 (6): 761-785.

49. Oltra, V. (2005): Knowledge management effectiveness factors: The role of HRM. Journal of Knowledge Management, 9(4): 70-86.

50. Pajares, F. (1997): Current directions in self-efficacy research. In M. Maehr \& P. R. Pintrich (Eds.). Advances in motivation and achievement, Greenwich, CT: JAI Press, 10: 1-49.

51. Pajares, F. (2002): Gender and perceived self-efficacy in self-regulated learning. Theory into Practice, 41: 116125.

52. Panahi, S., Watson, J. and Partridge, H. (2012): Social media and tacit knowledge sharing- Developing a conceptual model. International Journal of Social, Behavioral, Educational, Economic, Business and Industrial Engineering, 6(4): 648-655.

53. Pintrich, P. R. and De Goot, E. V. (1990): Motivational and self-regulated learning components of classroom academic performance. Journal of Educational Psychology, 82(1): 33-40.

54. Prochaska, J. O., Redding, C. A., and Evers, K. (1997): The transtheoretical model of change. In Health behavior and health education: Theory, research, and practice (eds.) K. Glanz, F. M. Lewis and B. K. Rimer, pp. 60-84. San Francisco: Jossey-Bass.

55. Professional challenge and resolution of professional disagreement (2015), A guide to inter-agency working to safeguard and promote the welfare of children, HM Government, Retrived from http://www.teescpp.org.uk/professional-challenge

56. Rehman, M., Mahmood, A. K. B., Salleh, R. \& Amin, A. (2011): Review of factors affecting knowledge sharing behavior. International conference on e-business, management and economics, IACSIT Press, Hong Kong, 3: 223-227.

57. Rogers, E. M. (1995): Diffusion of innovations (4th ed.). New York: The Free Press.

58. Sachs, J. (2001): Teacher professional identity- Competing discourses, competing outcomes. Journal of Education Policy, 16(2): 149-161.

59. Schaufeli, W. B., Bakker, A. B., \& Salanova, M. (2006): The measurement of work engagement with a short questionnaire. Educational and Psychological Measurement, 66(4): 701-716.

60. Schaufeli, W. B., \& Salanova, M. (2011): Work engagement-On how to better catch a slippery concept. European Journal of Work and Organizational Psychology, 20(1): 39-46.

61. Selamat, M. H. and Choudrie, J. (2004): The diffusion of tacit knowledge and its implications on information systems-The role of meta-abilities. Journal of Knowledge Management, 8: 128-139.

62. Sherer, M., Maddux, J. E., Mercandante, B., Prentice-Dunn, S., Jacobs, B. and Rogers, R. W. (1982): The self efficacy scale-Construction and validation. Psychological Reports, 51: 663-671.

63. Shuell, T. J. (1988): The role of the student in learning from instruction. Contemp Educ Psychol., 13: $276-295$.

64. Siemsen, E., Balasubramanian, S., \& Roth, A. V. (2007): Incentives that induce task-related effort, helping, and knowledge sharing in workgroups. Management Science, 53(10): 1533-1550.

65. Srivastava, R. (2007): The Healthcare Professional's Guide to Clinical Cultural Competence. Elsevier Health Sciences, pp- IX.

66. Subramaniam, M. \& Youndt, M. A. (2005): The influence of intellectual capital on the types of innovative capabilities. Academy of Management Review, 48: 450-463.

67. Swick H. M, Szenas, P., Danoff, D. and Whitcomb, M. E. (1999): Teaching professionalism in undergraduate medical education. JAMA, 282:830-832. 
68. Teece, D. J., Pisano, G. \& Shuen, A. (1997): Dynamic capabilities and strategic management. Strategic Management Journal, 18: 509-533.

69. Vanka S., Sriram, K. and Agarwal, A. (2007): Computer Society of India-Special Interest Group on Egovernance. 5th International Conference on E-governance (ICEG), 28-30 December, Hyderabad, India.

70. Wahab, S. A., Abdullah, H., Uli, J. \& Rose, R. C. (2010): Inter-firm technology transfer and performance in international joint venture firms. International Journal of Business and Management, 5: 93-103.

71. Wang, S. \& Noe, R. A. (2010): Knowledge sharing-A review and directions for future research. Human Resource Management Review, 20: 115-131.

72. Wasko, M. M. \& Faraj, S. (2000): It is what one does-Why people participate and help others in electronic communities of practice. The Journal of Strategic Information Systems, 9(2-3), 155-173.

73. Weert, T. J. V. (2006): Education of the twenty-first century: New professionalism in lifelong learning, knowledge development and knowledge sharing. Education and Information Technologies, 11(3-4): $217-237$.

74. Wingrave, M. and McMahon, M. (2016): Professionalisation through academicisation-Valuing and developing the early year's sector in Scotland. Professional Development in Education, 42(5): 710-731. 